\title{
Avaliação in vitro da patogenicidade dos isolados CG17, EP01 e 986 do fungo Beauveria bassiana (balsamo) Vuillemin sobre larvas do carrapato Anocentor nitens (Neumann, 1897) (Acari: Ixodidae)
}

\author{
Patogenicity of isolates CG17, EP01 and 986 of the fungi Beauveria \\ bassiana on larvae of the tick Anocentor nitens (Neumann, 1897) (Acari: \\ Ixodidae) in laboratory
}

\author{
Silvia Gonzalez Monteiro, * Vânia Rita Elias Pinheiro Bittencourt, ** Erik Daemon“
}

\begin{abstract}
Resumo
A patogenicidade in vitro de três isolados do fungo Beauveria bassiana, CG17 e EP01 e 986 foi avaliada em larvas do carrapato Anocentor nitens mantidas em temperatura controlada $\left(27^{\circ} \mathrm{C}\right.$ e $80 \%$ U.R.). A susceptibilidade das larvas aos isolados foi determinada experimentalmente por imersão de grupos de larvas não alimentadas com $25 \mathrm{mg}$ de larvas por grupo, durante três minutos, em quatro concentrações $\left(10^{5}, 10^{6}, 10^{7} \mathrm{e} 10^{8}\right.$ conídios/ml) de cada isolado e um grupo controle imerso em água (com dez repetições para cada tratamento). Após dez dias de infecção, a concentração $10^{8}$ causou a mortalidade de aproximadamente $93 \%$ das larvas para todos os isolados, e a concentração $10^{5}$ causou a mortalidade de $7,6 \%, 17,5 \%$ e $43 \%$, nos tratamentos com os isolados 986, EP01 e CG17, respectivamente. A mortalidade média de larvas do grupo controle não excedeu a $0,9 \%$, fato este que demonstra o poder patogênico deste fungo em larvas de $A$. nitens. A CL 50 para os isolados 986 , CG17 e EP01 foi $1,8 \times 10^{7} ; 1,6 \times 10^{6}$ e $2,5 \times 10^{7}$, respectivamente.
\end{abstract}

Palavras-chave: Anocentor nitens, Beauveria bassiana, fungos entomopatogênicos, controle microbiano.

\begin{abstract}
The in vitro pathogenicity of three isolates of the fungi Beauveria bassiana (CG17, EP01 and 986) were evaluated against the larvae of Anocentor nitens ticks under controlled conditions $\left(27^{\circ} \mathrm{C} ; 80 \% \mathrm{RH}\right)$. The susceptibility of its larvae to the isolated was experimentally determined by immersion of groups of larvae weighting $25 \mathrm{mg}$ each group, during three minutes in four different suspension $\left(10^{8}, 10^{7}, 10^{6}\right.$, and $10^{5}$ conidia/ml), and a control group immersed in water (ten repetitions for each treatment). After 10 days of infection, the concentrations of $10^{8}$ conidia/ml caused a mortality of approximately $93 \%$ of the larvae for all isolates, and the concentration $10^{5}$ caused a mortality of 7,6,17,5 and $43 \%$, in treatments with isolated 986 , EP01 and CG17, respectively. The mean mortality in control group was $0,9 \%$. The results proves the pathogenicity of these fungi in $A$. nitens larvae. The LC 50 of 986, CG17 and EP01 were 1,8 × 107 $1,6 \times 10^{6}$ and $2,5 \times 10^{7}$ respectively.
\end{abstract}

Keywords: Anocentor nitens, Beauveria bassiana, fungi, control microbial.

\section{Introdução}

O carrapato Anocentor nitens pertence à família Ixodidae e é responsável pela transmissão de vários agentes causadores de enfermidades em eqüídeos. Denning (1988) cita esta espécie como transmissora de Piroplasmose eqüina. Além disso, a lesão causada por sua picada pode servir de porta de entrada para bactérias e miíases.

Beauveria bassiana é um fungo Deuteromiceto encontrado comumente no solo e considerado por diversos autores (Kaaya et al., 1996, Mwangi, 1991, Bittencourt et al., 1996) como entomopatogênico para diferentes espécies de carra. pato, sendo bastante empregado no controle biológico de plantas. Uma grande vantagem desse fungo sobre os pesticidas convencionais é a sua persistência sobre a população hospedeira, redução da longevidade e altas taxas de mortalidade em larvas e adultos das populações de insetos.

O fungo $B$. bassiana é uma das espécies mais conhecidas para o controle de pragas, e isso se deve à sua ampla distribuição geográfica, variedade de hospedeiros e ocorrência em condições naturais de forma enzoótica ou provocando epizootias em algumas espécies de insetos pragas.

No Brasil, o trabalho de Monteiro et al. (1998c) demonstrou que o uso de suspensões de $B$. bassiana em larvas de

\footnotetext{
* Doutoranda do CPGMV-PV, bolsista CAPES.

* Departamento de Parasitologia Animal, Instituto de Biologia, Universidade Federal Rural do Rio de Janeiro, Seropédica, RJ, Brasil, CEP 23890-000
} 
Rhipicephalus sanguineus originou uma mortalidade proporcional a concentração dos conídios utilizada.

Monteiro et al. (1998a), ao utilizar esse isolado em fêmeas ingurgitadas de $A$. nitens verificaram uma diminuição gradativa, inversamente proporcional à concentração utilizada no período de postura, no peso da massa de ovos, no período médio de sobrevivência, no período de incubação, no periodo de eclosão e nos índices de eficiência reprodutiva $e$ nutricional. Contrariamente, houve aumento proporcional à concentração utilizada no peso das quenóginas e na mortalidade de larvas.

Monteiro et al. (1998b) testaram esse mesmo isolado em ovos de $R$. sanguineus e constatou que a porcentagem de eclosão de larvas oriundas desses ovos foi inferior a $30 \%$ nos grupos tratados com a suspensão $10^{8}$ conídios $/ \mathrm{ml}$.

O objetivo do presente trabalho foi avaliar o efeito in vitro dos isolados CG17, EP01 e 986 do fungo $B$. bassiana sobre larvas do carrapato $A$. nitens em condições de temperatura e umidade controlada.

\section{Material e métodos}

Fêmeas do carrapato $A$. nitens coletadas de eqüinos naturalmente infestados foram lavadas, secas, colocadas em placas de Petri isoladamente e mantidas em câmara climatizada $\left(27^{\circ} \mathrm{C}\right.$ e $80 \%$ UR) para obtenção da postura.

Após o início da postura foram feitas pesagens de $25 \mathrm{mg}$ de ovos/cada. Esses ovos foram postos em tubos de ensaio vedados com algodão hidrófilo na extremidade e mantidos nas mesmas condições climáticas citadas anteriormente para eclosão das larvas (aproximadamente 800 larvas).

Os isolados utilizados foram o EP01 (isolado de Cosmopolites sordidus), CG17 (isolado de Hypothenemus hampei) e 986 (isolado de Boophilus microplus). Estes isolados foram repicados previamente em meio de arroz (Alves, 1998) para a obtenção dos conídios e com o auxílio de câmara de Neubauer, foram preparadas quatro suspensões com diferentes concentrações $\left(10^{8}, 10^{7}, 10^{6}, 10^{5}\right.$ conídios $\left./ \mathrm{ml}\right)$ de cada um dos isolados contendo água destilada e $1 \%$ de espalhante adesivo (Tween 80 ) mais um grupo controle contendo apenas água destilada e $1 \%$ de espalhante adesivo.

Após a eclosão, cada tubo de ensaio contendo as $25 \mathrm{mg}$ de larvas foi imerso com três mililitros de cada suspensão durante três minutos após os quais, os tubos foram invertidos para o escoamento através do algodão do excesso de suspensão. Foram utilizadas dez repetições em cada tratamento.

Os parâmetros analisados através da análise de variância ANOVA e MICROPROBIT foram: porcentagem de mortalidade de larvas e concentração letal para 50 e 90\% (CL 50 e CL 90) da população de larvas.
Tabela 1: Média e desvio-padrão da mortalidade de larvas de Anocentor nitens tratadas com os isolados CG17, EP01 e 986 do fungo Beauveria bassiana.

\begin{tabular}{|c|c|c|c|c|}
\hline \multirow{2}{*}{$\begin{array}{l}\text { Concentração de } \\
\text { conídios/ ml }\end{array}$} & & \multicolumn{3}{|c|}{ Mortalidade das larvas } \\
\hline & & Isolado CG17 & Isolado EP01 & Isolado 986 \\
\hline \multirow[t]{2}{*}{$10^{8}$} & $x$ & $99,3 \mathrm{a}$ & $99,9 \mathrm{a}$ & $93,6 \mathrm{a}$ \\
\hline & $\mathrm{S}$ & 1,5 & 0,3 & 8,3 \\
\hline \multirow[t]{2}{*}{$10^{7}$} & $x$ & $91,2 \mathrm{a}$ & $83,5 \mathrm{~b}$ & $36 \mathrm{~b}$ \\
\hline & $s$ & 14,3 & 19 & 13,4 \\
\hline \multirow[t]{2}{*}{$10^{6}$} & $x$ & $92,7 \mathrm{a}$ & $34 \mathrm{c}$ & $17 \mathrm{~b}$ \\
\hline & $\mathbf{s}$ & 7,6 & 29,5 & 8,2 \\
\hline \multirow[t]{2}{*}{$10^{5}$} & $x$ & $43 \mathrm{~b}$ & $17,5 \mathrm{c}$ & $7,6 \mathrm{c}$ \\
\hline & S & 25,8 & 13,5 & 6,3 \\
\hline \multirow[t]{2}{*}{ Controle } & $x$ & $0,9 \mathrm{c}$ & $0,9 \mathrm{~d}$ & $0.9 \mathrm{~d}$ \\
\hline & $\mathbf{s}$ & 0,7 & 0,7 & 0,7 \\
\hline
\end{tabular}

As médias seguidas pela mesma letra, numa mesma coluna, não diferem entre si.

$x=$ média; $\mathrm{s}=$ desvio-padrão

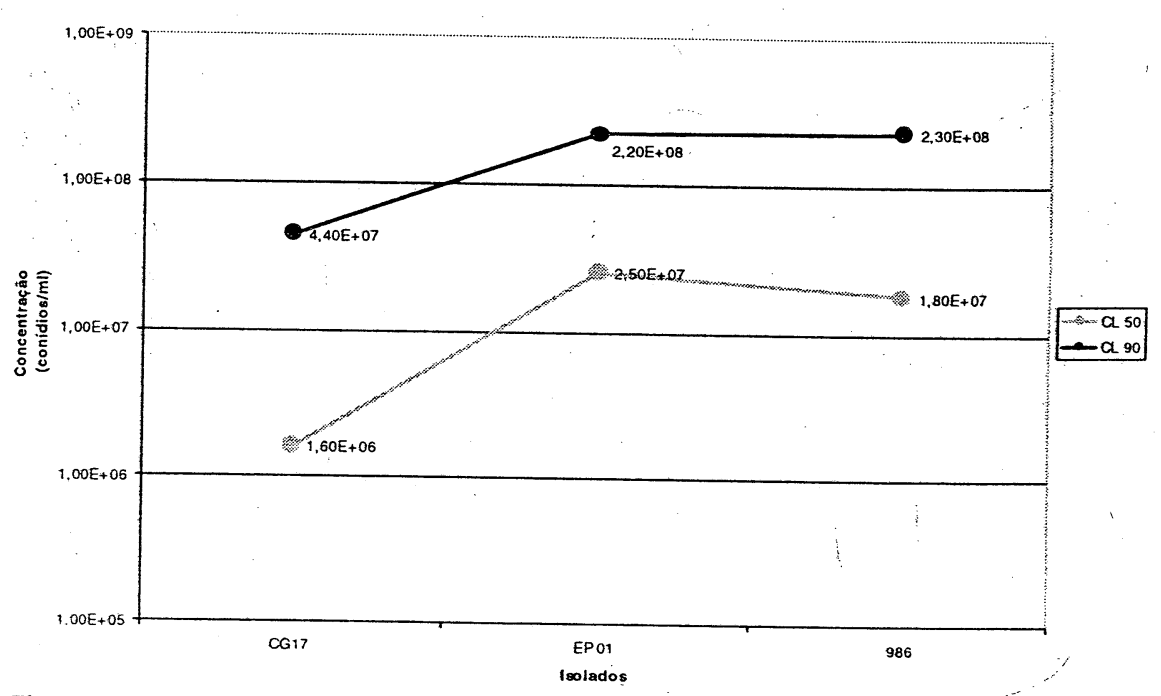

Figura1: Concentração letal para 50 e $90 \%$ da população de larvas de Anocentor nitens tratadas com os isolados CG17, EP01 e 986 do fungo Beauveria bassiana.

\section{Resultados e discussão}

Os percentuais de mortalidade observados nos bioensaios com larvas com suas respectivas médias e desvios-padrão estão demonstrados na Tabela 1 , e as concentrações letais para $50 \%$ e $90 \%$ da população de larvas estão demonstradas na Figura 1.

Observou-se que o percentual de mortalidade médio verificado nos grupos tratados com os diferentes isolados do fungo B. bassiana foi maior que o observado no grupo controle. Dez dias após a infecção, as larvas tratadas com os isolados de B. bassiana na concentração $10^{8}$ tiveram mortalidade superior a $93 \%$, sendo que a mortalidade foi proporcional à concentração de conidios utilizada em todos os tratamentos com os diferentes isolados. $\mathrm{Na}$ concentração $10^{5}$ a mortalidade foi de 
$43 \%, 17,5 \%$ e 7,6 para os isolados CG17, EP01 e 986 , respectivamente, enquanto a média de mortalidade do grupo controle foi de 0,9\%.

$\mathrm{Na}$ análise de próbites a concentração letal para $50 \%$ dos isolados CG17, EP01 e 986 ficaram em 1,6 $\times 10^{6}$ conídios $/ \mathrm{ml}$, $2,5 \times 10^{7}$ conídios $/ \mathrm{ml}$, e 1,8 $\times 10^{7}$ respectivamente e a concentração letal para $90 \%$ da população de larvas foi superior para o isolado $986\left(2,3 \times 10^{8}\right.$ conídios $\left./ \mathrm{ml}\right)$ se comparado aos isolados EP01 (2,2 x $10^{8}$ conídios $\left./ \mathrm{ml}\right)$ e CG17 (4,4 x 107).

$O$ trabalho de Monteiro et al. (1998c) utilizando os isolados 747 e 986 deste mesmo fungo entomopatogênico infectando larvas de $R$. sanguineus mantidas nas mesmas condições de temperatura e umidade deste trabalho, demonstraram uma mortalidade de $100 \%$ das larvas após dez dias da infecção na concentração $10^{8}$ conídios $/ \mathrm{ml}$ para ambos isolados. Em um trabalho similar, Bittencourt et al. (1996) avaliaram a ação dos mesmos isolados de B. bassiana em larvas do carrapato B. microplus e observaram $82 \%$ de mortalidade máxima para

\section{Referências}

ALVES, S. B. Controle Microbiano de Insetos. 2. ed., São Paulo: FEALQ, Piracicaba, 1998, 1163p.

BITTENCOURT, V. R. E. P.; PERALVA, S.L.F.S.; VIEGAS, E. C.; ALVES S. B. Avaliação dos efeitos do contato de Beauveria bassiana (Bals.) Vuill. com ovos e larvas de Boophilus microplus (Canestrini, 1887) (Acari: Ixodidae). Rev. Bras. Parasitol. Vet., v. 5, n. 2, p. 81-84, 1996. DENNING, F. Unsuccessul attemps to transmit Amblyomma cajennense. 1988. 112 p. Tese (Doutorado) - Escola de Medicina Veterinária, Hannover.

KAAYA, G. P.; MWANGI, E. N.; OUNA, E. A. Prospects for Biological Control of Livestock Ticks, Rhipicephalus appendiculatusand Amblyomma variegatum, Using the Entomogenous Fungi Beauveria bassiana and Metarhizium anisopliae. J. Invert. Pathol., v. 67, p. 15-20, 1996. a concentração $10^{8}$ conídios $/ \mathrm{ml}$, fatos esses que mostram que o percentual de mortalidade observado nos experimentos está relacionado à especificidade dos isolados para cada espécie de carrapato envolvida. $\mathrm{Na}$ análise de próbites realizada com os dados referentes ao percentual de mortalidade dos isolados de $B$. bassiana testados neste experimento verificou-se que as concentrações letais para $50 \%$ da população ficaram próximas às encontradas no trabalho de Bittencourt et al. (1996) com 6,8 × $10^{6}$ e $1,01 \times 10^{7}$ conídios $/ \mathrm{ml}$ e superiores ao encontrado no trabalho de Monteiro et al. (1998c) $\left(2,2 \times 10^{5}\right.$ e 2,1 × $10^{6}$ conídios $\left./ \mathrm{ml}\right)$, o que pode reforçar a hipótese de maior ou menor especificidade para cada espécie em questão, visto que Monteiro et al. (1998c) trabalharam com $R$. sanguineus.

Os resultados encontrados no presente trabalho mostraram uma redução da quantidade de larvas que sobreviveram à infecção e são similares aos encontrados na literatura, o que com relação a outras espécies de carrapatos, nos leva a concluir que estes isolados são patogênicos para larvas de $A$. nitens.

MONTEIRO, S.G.;BITTENCOURT, V.R.E.P.; DAEMON, E.; FACCINI, J.L $H$. Patogenicidade dos fungos entomopatogênicos Metarhizium anisopliae e Beauveria bassiana em larvas de Rhipicephalus sanguineus (Acari: Ixodidae). Rev. Bras. Parasitol. Vet., v. 7, n. 2, p. 113-116, 1998c.

MONTEIRO, S. G.; CARNEIRO, M. E.; BITTENCOURT, V. R. E. P.; DAEMON. E. Efeito do isolado 986 do fungo Beauveria bassiana (Bals.) Vuill sobre fêmeas ingurgitadas de Anocentor nitens NEUMANN 1897. Arq. Bras. Med. Vet. e Zootec., v. 50, n. 6, p. 673-676, 1998a. MONTEIRO, S. G.;BITTENCOURT, V. R. E. P.; DAEMON, E.; FACCINI,J. L. H. Efeito dos fungos entomopatogênicos Metarhizium anisopliae e Beauveria bassiana em ovos de Rhipicephalus sanguineus (Acari: Ixodidae). Rev. Ciência Rural, v. 28, n. 3, p. 461-466, 1998b.

MWANGI, E. N.; DIPEOLU, O. O.; NEWSON, R. M.; KAAYA, G. P.; HASSAN, S. M. Predators, Parasitoids and Pathogens of Ticks: a Review. Bioc. Sci. Technol., v. 1, p. 147-156, 1991. 